\title{
Eight Young Scientists to be Presented with Student Awards
}

Again this year, Student Awards will be presented to a group of graduate students who are conducting outstanding research in a topic to be addressed by one of the symposia at the Spring Meeting. The chairman of the MRS Awards Committee, Elton Kaufmann, announced that awards will be presented to eight students who are presenting papers in seven of the Spring Meeting symposia. A large number of applications were received for these awards, and the Awards Committee was faced with the difficult task of determining the recipients of a limited number of awards from a large group of highly qualified individuals. Kaufmann states, "The purpose of the Graduate Student Award Program is to recognize the contributions of graduate students to materials research, and to encourage the active participation of students in the meetings and other activities of MRS. The fact that a large number of applications have been received for these awards demonstrates that a growing number of highly qualified students are becoming aware of the programs and objectives of the Society. Student Awards will also be presented at the Fall Meeting and students are encouraged to submit applications now for the Fall Meeting awards."
The award recipients and the titles of their contributions to the Spring Meeting program are listed below.

\section{Stephanie M. Koch}

Stanford University

Field of Study: Materials Science, Symposium A: Heteroepitaxy on Silicon Technology, Paper: The Growth of GaAs on $\mathrm{Si}$ by Molecular Beam Epitaxy

\section{Leslie A. Kolodziejski}

Purdue University

Field of Study: Electrical Engineering, Symposium B: Compound Semiconductor Materials, Paper: MBE of II-VI Semiconductors

\section{Douglas A. Doughty}

University of Wisconsin-Madison

Field of Study: Physics, Symposium C: Plasma Processing, Paper: An Investigation of the Cathode Fall

\section{Jeffrey C. McCallum}

University of Melloourne

Field of Study: Applied Nuclear Physics, Symposium D: Materials Characterization, Paper: Channeling Contrast Microscopy: A Powerful Technique for Examining Semiconductor Structures

\section{Karen K. Gleason}

University of California-Berkeley

Field of Study: Chemical Engineering, Symposium E: Materials Issues in Amorphous Semiconductor Technology, Paper: Multiple Quantum NMR Study of Hydrogen Clustering in Amorphous Silicon

\section{Chris M. Gronet}

Stanford Unitersity

Field of Study: Semiconductor Processing, Symposium F: Materials Issues in Silicon Integrated Circuit Processing, Paper: Limited Reaction Processing: Heteroepitaxial Deposition

\section{Kenton D. Budd}

Uniersity of Illinois-Urbana

Field of Study: Ceramic Engineering, Symposium H: Better Ceramics Through Chemistry, Paper: Sol-Gel Processing of $\mathrm{PbTiO}_{3}$ Thin Films

\section{Burtrand I. Lee}

University of Florida-Gainesville'

Field of Study: Ceramic Science, Symposium H: Better Ceramics Through Chemistry, Paper: Silicon Carbide from Organosilanes and Applications in Silica Gel Glass Composites

\section{Membership in the Materials Research Society}

The Materials Research Society is dedicated to fostering the exchange of scientific information across the many disciplines involved in materials research. Membership benefits include:

\author{
Subscription to Journal of Materials Research* \\ Subscription to MRS BULLETIN \\ Discounts on MRS proceedings \\ Discounts on special books published by other leading scientific publishers \\ Discount subscription to Materials Letters \\ Information on upcoming MRS meetings and short courses \\ Copy of the MRS Membership Directory \\ Discount subscriptions on journals published by the American \\ Institute of Physics
}

*Regular members only. Student members may subscribe for $\$ 15$.

To join the Society, complete the MRS Membership Application inside this issue. If you are already a member, pass the application on to an interested colleague. 